\title{
Milliosmole per Liter
}

National Cancer Institute

\section{Source}

National Cancer Institute. Milliosmole per Liter. NCI Thesaurus. Code C122214.

A unit of osmotic pressure equal to one thousandth of an osmole per unit of volume equal to one Liter. 